\title{
Role of Stanyadushti as an etiological factor in malnourished children
}

\section{Kate Kirti Shrikantrao}

Asso. Professor, Dept. of Kaumarbhritya Tantra,

ASS Ayurved College, Panchavati, Nashik

Corresponding Author: 9960394413; Email ID kate.kirti@gamil.com

\section{Abstract:}

Stanyadushti described by all Acharyas in our Samhitas is an unique topic related with feeding mothers \&children.when breastmilk gets vitiated due to vitiated doshas in mother then it causes disturbance of metabolism in children (infants) receiving same.It can be said that Stanyadushti plays a key role as an etiological factor in malnutrition especially in young infants.

KEYWORD: stanyadushti, malnutrition, etiological factors 


\section{INTRODUTION:}

Breastmilk is thought to be the best form of nutrition for neonates \& infants. This dynamic fluid provides a diverse variety of bioactive substances to the developing infants during critical periods of brain, immune system \& gut development. Acharya Vagbhatmentioned it as best thing for the baby's growth \& development.

But when this breastmilk gets vitiated due to vitiated doshas in mother, then it leads to diseases. The biochemical \& metabolic changes in mother are transferred through milk to the child. The diet (ahara) \& activities(vihara) of the mother which are responsible for aggravation of doshas in her body in turn results in diseases caused by the same dosha in the infant also.Depending upon the dosha affecting breastmilk, various symptoms of malnutrition are seen in babies.

Malnutrition ins a pathological state resulting from a relative or absolute deficiency or excess of one or more essential nutrients ${ }^{3}$.This is either due to an inadequate diet or problems absorbing nutrients from food.
For young infants aging 6 months to one $\&$ half year, breastmilk is the prime source of food\& nutrients. When this breastmilk is vitiated by doshas the nutrients are not properly absorbed by the baby leading to malnutrition.

Material \& methods

Referrences from our Brihattrayihelp to enlighten this concept of stanyadushti as a hetu for malnutrition.

Etopathogenesis of milk vitiation

Intake of unsuitable and incompatible items during indigestion(ajirna), irregular and excessive intake of food, regular intake of salty, sour, pungent alkaline and decomposed food items, mental and physical stress, night awakening, excessive mental work, suppression of natural urges \&forcibly initiation of natural urges, day sleep, excessive indulgence in wine, lack of physical exercise, injury, anger, lean \& thin caused by illnesses, dosha reaching the milk- carrying vessels and result in vitiation of breastmilk.

Disorders / symptoms produced byVatadoshavitiated milk-

Due to use of ruksha etc. properties containing dietetics \& mode of life causes vitiation of vata and taste of milk gets altered

\section{Vitiated vata}

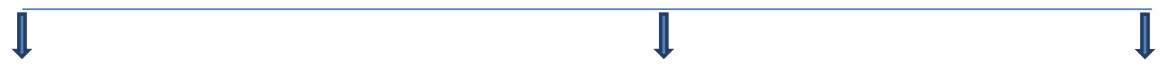

Vairasyata in milkphena-samghataRoukshya
(Abnormal taste, tastelessBM)
(frothy)
(non unctuousness) 


\section{$\Downarrow$}

Normal sweet taste of

is altered

\section{$\Downarrow$}

child either refuse to suck this

milk or gets ematitation

\section{$\Downarrow$}

Altered growth \&Development
$\Downarrow$

reaches to the breast vitiation of vata

churns the milk

formation of froth

$\Downarrow$

Breast milk is ejected

with difficulty (i.e. lacking Sneha or

Malnutrition.Breast milk is lacking its

normal consistency (probably loss of strength (can be

due to altered composition

said as loss of immunity

of nutrients) to combat with diseases)

Causes weak cry. $\quad$ Child may suffer from

Retention \& suppression of loss of vigor \& vitality.

Feces, urine\& flatus.

Altered growth

Malnutrition.

Malnutrition.

\section{Vitiated pitta}

Vaivarnya

Dourgandhya

(Discoloration)

(Abnormal smell)

Website: http://www.ayurlog.com Volume $6^{\text {th }} \mid$ Issue: $1^{\text {st }}$ January-March 2018 
Vitiated pitta in breast produces blue, yellow /black hue in milk.
Pitta vitiated milk produces foul smell in the milk

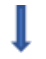

Child fed on this milk suffers Child who is sucking this milk suffers

from excessive perspiration, from Pandu (Anemia) \&Kamala

thirst and diarrhoea.(Jaundice) probably due to altered Agni

$\Downarrow$

This results in loss of nutrients child from body.

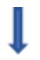

Altered growth

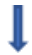

Malnutrition.
Altered absorption of nutrients in in child getting this milk

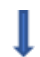

Altered growth \& development

$\downarrow$ Malnutrition.

Vitiated kapha

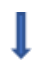

Atisnigdha

excessiveunctuousness)

$\downarrow$

Kaphadoshaby Vitiated kaphamakes breast milk
Vitiated kaphareaches

Unctuousproperty excessive pichchila (slippery)

into breast $\&$ makes breast

$\Downarrow$ milk gurui.e. heavy for

Milk is highly unctuous

Breast milk becomes viscous

digestion $\&$ produces

\section{$\downarrow$}

Child getting this milk

develops vomiting's $\downarrow$ heaviness in the body

Not easily digested $\downarrow$

Produces Hridroga 
tenesmus, excessive salivation Excessive salivation, dullness, (cardiac disorders)

(features of indigestion) edema of eyes \& facePratishyay, Ksheeralasak

$\llbracket$ like kaphajvikara

All this strotasaare constantly

Malnutrition

smeared or covered

Altered nutrition \&

absorption

$\llbracket$

Affected Dhatu poshana

$\downarrow$

Child suffers from excessive

Sleep, dyspnea, cough,

excessive salivation, giddiness

$\downarrow$

Altered absorption of nutrients

Malnutrition.

Thus, this breast milk which is a complete food for a baby upto first 6 months of life, plays an important role in maintaining health of the baby. Breast milk, whenever gets vitiated it creates disturbance of equilibrium in the baby who consumes it \& produces symptoms, group of symptoms or a disease depending up on the anshansha Kalpana of dosha in breast milk.

\section{Sampraptiof}

dushtastanyajanyavikaras. Most of the times it is seen that these doshas alter with the metabolism \& growth \& development of baby.

Study of these different types of stanyadushtihelps in ruling out the exact cause of failure to grow or thrive in infants. It also helps in management of malnutrition caused by dushtstanyaaccording to dosha, prabhav\&guna (hetuviparitchikitsa) shodhanaofdhatriis the best treatment suggested by the samhitas. Practically it is seen that lactating mothers are reluctant for shodhana likeVamana or virechana.

In this situation stanyashodhakdravyasare helpful in managing the condition. According to sampraptijanyadosha\&guna, stanyashodhakdravyascan be used to treat the malnutrition caused by stanyadushti.

Considering this we can conclude that stanyadushtiplays an important role in etiology of malnutrition in infants. Study 
of these stanyadushtikarfactors helps in both prevention \& management of malnutrition in infants. In the management of dushtastnyajanyavikaras both mothers \& baby are treated, method of which is elaborated in following chart.

\section{Treatementof dhatri}

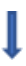

Stanyajanan

Doshchikitsa

This treatment is given $\downarrow$

Drugs used for according todifferent shamanShodhan improvement amount lakshanasi.e. Vaivarnya $\downarrow$

\& quality (Gunas) of vaigandhyaetc.[ Which Lakshanikfirst vaman breast milk. is mentioned in detail [Stanyashodhan] is given.

\section{by AchryaCharaka] $\mathbb{\Downarrow}$}

\section{AaharVirechan}

[ ModificationIn diet.]

\section{AvashishtadoshnashanAahar}

ForVatta - Shashtikshali

For Pitta - Priyangu

ForKaphaYavakordush

\section{CONCLUSION}

There are many diseases like Phakka, parigarbhikin whichdushtstanyais mentioned as one of the causative factor for the disease. Also, these diseases simulate with malnutrition. But in these diseases there are some special conditions where stanyadushti acts as etiological factor like garbhajaphakka.
Apart from these special diseases in day to day life we see children with symptoms of malnutrition specially undernutrition. These symptoms may or may not be the part of actual disease but the etiological/ causative factor behind these symptom is surely stanyadushti which has been neglected for years.

So, this article helps in understanding the exact role of individual type of stanyadushtias an etiological factor of malnutrition. Once the exact causative factor is detected. It 
becomes easy to prevent $\&$ treat the condition like malnutrition in infants and young children. Along with malnourished infants their mothers can be treated for stanyadushtiand ongoing smaprapti can be prevented and the condition can be controlled much earlier. There is future scope in the field of research to find out specific factors affecting metabolism of breast milk in stanyadushti.

\section{References:}

1. Charaka Samhita volume 1 English commentary by Prof.K.R. ShrikanthaMurthy,Chaukhamba publications Varanasi. $1^{\text {st }}$ edition 2004

2. Charaka Samhita with chakrapani commentary \&Vidyotini commentary by Pt. Kashinath Shastri, $1^{\text {st }}$ edition , ${ }^{\text {st }}$ part,ChaukhambaSankrit series,Varanasi,1994.

3. Charak Samhita part I \& II hindi commentary Ayushi on Charak Samhita \&ayurved Deepika(chakrapanikrita) by Vd.Harishchandsinghkushavaha,Chau
khambaOrientalia Varanasi.(reprint edition 2011)

4. Ashtanghridayam, vol. I\&II translated by Prof. K.K. ShrikanthMurthy,chukhambakrishnad as academy Varanasi.(reprint edition 2010)

5. Ashtang Sangraha of Vgbhatavoi.I,II,III English translated by Prof.K.K. Shrikanth MurthyChaukhambaOrientalia Varanasi.(reprint edition 2009)

6. Kashyapa Samhita or Vriddhajeevakiyatantra,edited by Prof. P.V.Tiwari\& English translation \& commentary by Visvabharati, Varanasi. Reprint 2008

7. Prasutitanatra \& Strirog by Dr. P.V. Tiwari, ChaukhambaOrientalia Varanasi, $1^{\text {st }}$ edition 1986

8. Yogaratnakara A complete Treatise on Ayurveda part I \& II Edited \& Translated by Dr. Asha Kumari Dr.PremvatiTiwari,Chaukhamba Vishwabharati,Varanasi. ${ }^{\text {st }} \quad$ edition 2010

9. Textbook of BalrogaKaumarbhritya Part I \& II, Dr. B.M. Singh,ChaukhambaOrientalia Varanasi, 2015

\section{Cite this article:}

\section{Role of Stanyadushti as an etiological factor in malnourished children} Kate Kirti Shrikantrao

Ayurlog: National Journal of Research in Ayurved $S_{\text {cience-2017; 6(1): 1-7 }}$ 